\title{
PELAYANAN KEPERAWATAN PRIMA BERBASIS BUDAYA BERPENGARUH TERHADAP TINGKAT KEPUASAN PASIEN DI RUMAH SAKIT
}

\author{
Suroso $^{1,2^{*}}$, Rr Tutik Sri Haryati ${ }^{3}$, Mustikasari $^{3}$, Enie Novieastari $^{3}$ \\ 1. Rumah Sakit TNI AL Dokter Soedibjo Sardadi, Jayapura 59112, Indonesia \\ 2. Program Studi Magister, Fakultas Ilmu Keperawatan, Universitas Indonesia, Depok 16424, Indonesia \\ 3. Fakultas Ilmu Keperawatan, Universitas Indonesia, Depok 16424, Indonesia \\ *E-mail: nifina_farhan@yahoo.com
}

\begin{abstract}
Abstrak
Kepuasan pelanggan terhadap pelayanan kesehatan yang diterima dapat diwujudkan dengan melaksanakan pelayanan prima. Penelitian ini bertujuan mengetahui pengaruh pelayanan prima berbasis budaya terhadap tingkat kepuasan pasien di rumah sakit. Metode penelitian menggunakan quasi experiment dengan rancangan pre and post with control group design. Jumlah sampel adalah tiga puluh lima perawat dan seratus empat puluh pasien. Teknik pengambilan sampel untuk perawat menggunakan total sampling, sementara untuk pasien dilakukan dengan consecutive sampling. Hasil penelitian menunjukkan adanya pengaruh yang bermakna $(\mathrm{p}<0,05)$ terhadap tingkat kepuasan pasien setelah perawat mendapatkan pelatihan pelayanan prima berbasis budaya pada sebelum dan sesudah di kelompok intervensi. Rekomendasi yang dapat diberikan adalah perlunya meningkatkan peran supervisi agar keberlangsungannya tetap terjaga. Selain itu, untuk penelitian berikut dapat juga dilakukan dengan model triangulasi.
\end{abstract}

Kata kunci: budaya, keperawatan, kepuasan pasien, pelayanan prima

\begin{abstract}
Nursing Care Prima Culture-Based Influence to Patient Satisfaction in Hospitals. This research aimed to determine the effect of service excellent based on culture to patient satisfaction level in installation of hospitalization Hospital Jayapura. This research is a quasi experiment with pre and post with control group design. The number of samples is someone 35 nurses and 140 patients. The results showed have significant effect $(p<0.05)$ on the level of patient satisfaction after nurses receive training excellent service based onculture pre and post intervention group. Recommendations can be given is the need to enhance the role of supervision in order to maintain continuity, for the following research maybe done by triangulation models.
\end{abstract}

Keywords: culture, nursing, patient satisfaction, service excellence

\section{Pendahuluan}

Pelayanan prima dalam keperawatan adalah pelayanan yang berdasarkan perilaku caring, dengan sepuluh karatif caring. Menurut Leinenger dan McFarland (2002), yang didasarkan pada kebudayaan adalah suatu aspek esensial untuk memperoleh kesejahteraan, kesehatan, partumbuhan dan ketahanan, serta kemampuan untuk menghadapi rintangan maupun kematian. Perawatan yang mendasarkan budaya adalah bagian komprehensif serta holistik untuk mengetahui, menjelaskan, menginterpretasikan, dan memprediksikan fenomena asuhan keperawatan serta memberikan panduan dalam pengambilan keputusan dan tindakan keperawatan. Keperawatan transkultural adalah disiplin ilmu perawatan humanistik dan profesi yang memiliki tujuan utama untuk melayani individu dan kelompok.

Praktik perawatan dipengaruhi oleh keyakinan dan nilai budaya yang cenderung tertanam dalam pandangan dunia, bahasa, filosofi, agama, kekeluargaan, sosial, politik, pendidikan, ekonomi, 
teknologi, etnohistory, dan lingkungan kebudayaan. Keperawatan yang berdasarkan budaya dapat meningkatkan kepuasan pasien sehingga dapat memengaruhi derajat kesehatan dan kesejahteraan individu, keluarga, kelompok, dan komunitas di dalam lingkungannya. Keperawatan yang berdasarkan budaya dapat terwujud apabila pola, nilai budaya dan perawatan digunakan secara tepat, aman dan bermakna (Bhui, Warfa, Edonya, McKenzie, \& Bhugra, 2007).

Raso (2006) menyatakan bahwa memahami bahasa sangat penting. Ketidakmampuan untuk berkomunikasi tidak hanya membuat frustasi bagi kedua belah pihak, tetapi juga menimbulkan risiko keselamatan pasien dalam rangka untuk merencanakan dan mengoordinasikan sesuai perawatan. Douglas, et al., (2009) menyatakan bahwa perawat perlu mendapatkan pendidikan tentang budaya dalam melakukan pelayanan, sehingga perawat mempunyai kompetensi atau kemampuan tentang kebudayaan pasien yang dirawat. Standar praktik untuk kompetensi perawat berbasis budaya terdiri atas keadilan sosial, pemikiran kritis, pengetahuan tentang perawatan lintas budaya, praktik lintas budaya, sistem kesehatan dan organisasi, pemberdayaan dan advokasi pasien, tenaga kerja yang bermacam ragam budaya, pendidikan dan pelatihan, komunikasi lintas budaya, kepemimpinan lintas budaya, kebijakan pengembangan, dan penelitian berbasis evidence base.

Model keperawatan transkultural adalah panduan yang baik bagi perawat dalam memberikan pelayanan kepada pasien dengan struktur budaya masyarakat yang bermacam ragam (Gulbu, 2006; Maier-Lorentz, 2008; Foster \& Anderson, 2009).

Kemampuan tentang budaya dalam keperawatan profesional sangat penting untuk mengatasi masalah kesehatan pasien. Perawatan peka budaya mengelola konflik yang dapat menyebabkan frustrasi, baik kepada pasien maupun keluarga. Manfaat yang diperoleh dengan menyiapkan kompetensi budaya kesehatan adalah meningkatkan efisiensi waktu. Pasien lebih mendapat informasi dan dapat menurunkan rasa stress pada pasien dan tenaga perawat, kemampuan kompetensi peka budaya juga meningkatkan kepercayaan pasien dan kepuasan pasien (DeRosa \& Kochurka, 2006).

Nilai kultural adalah prinsip-prinsip atau kualitas yang dianut oleh suatu kelompok masyarakat dan diyakini tentang hal-hal baik dan berguna bagi kelompoknya. Setiap kelompok masyarakat mempunyai nilai-nilai yang berbeda. Perawat sebagai tenaga profesional harus mempunyai pengetahuan yang cukup tentang nilai-nilai yang dianut oleh kliennya sehingga interaksi dapat berjalan dengan baik (Sumijatun, 2011).

Perawat sebagai bagian dari sumberdaya manusia yang bekerja di rumah sakit (RS) memiliki nilai budaya tertentu, yang menyangkut masyarakat kecil dengan kebudayaannya sendiri yang sangat mirip dengan suatu desa petani atau suatu masyarakat rumpun kecil dengan suatu kebudayaan tertentu (Foster \& Anderson, 2009). Meskipun demikian, rumah sakit memiliki kebudayaannya sendiri, kebudayaan secara umum sulit untuk dicirikan, keperawatan merupakan ilmu tentang manusia dan pengalaman sehat-sakit manusia yang disampaikan melalui transaksi profesional, ilmiah, estetis, dan etis. Perawatan kesehatan yang benar adalah yang berfokus pada gaya hidup, kondisi sosial dan lingkungan, bukan proses diagnosa penyakit atau pengobatan (Watson, 2002; Tomey \& Alligood, 2006).

Menurut Bosek dan Savage (2007), perawat perlu melengkapi dirinya dengan cultural competency, terutama bagi perawat yang bertugas pada tatanan komunitas. Apabila klien dirujuk dan dirawat di rumah sakit, klien akan membawa budaya yang selama ini dianut sehingga perlu bantuan perawat dalam beradaptasi dengan lingkungannya yang baru. Kebiasaan hidup klien sehari-hari dapat berubah secara drastis, seperti kebiasaan makan, mandi, tidur, dan sebagainya. Oleh karena itu, perawat perlu memahami aspek budaya yang dianut kliennya. Dengan demikian, pengkajian perlu dilakukan secara komprehensif dan juga melibatkan orang-orang terdekat klien.

Penelitian ini dilakukan di sebuah rumah sakit di Papua dengan dilatarbelakangi bahwa pasien 
banyak mengeluh tentang sikap perawat yang kurang perhatian dalam pemberian pelayanan sebesar $48 \%$, perawat kurang komunikasi terhadap pasien dan keluarga 53\%, sikap perawat yang lambat dalam merespons keluhan atau panggilan pasien sebesar $46 \%$, sarana dan prasarana penunjang yang kurang memuaskan sebesar $30 \%$.

Berdasarkan hasil wawancara dengan lima orang perawat tentang tingkat kepuasan pasien didapatkan hasil bahwa hampir setiap bulan terjadi komplain atau keluhan baik dari pasien maupun keluarga. Keluhan yang dirasakan adalah sikap petugas administrasi yang kurang ramah, sikap perawat yang cerewet, judes, dan lamban dalam merespons keluhan pasien serta komunikasi yang kurang baik terhadap pasien.

Hasil observasi penulis juga mendapatkan bahwa sebagian besar perawat terutama yang shift sore atau malam tidak memakai seragam yang lengkap, ada yang memakai sandal jepit, ada yang tidak memakai kap, ada yang menggunakan seragam atasan saja, ada yang memakai seragam hanya bawahan saja, penampilan terlihat kurang rapi, dan kurang komunikasi kepada pasien. Berdasarkan kondisi tersebut, pertanyaan penelitian adalah "apakah ada pengaruh pelayanan prima berbasis budaya terhadap tingkat kepuasan pasien di rumah sakit X Jayapura?”

\section{Metode}

Penelitian ini adalah penelitian quasi experiment dengan rancangan pre and post with control group design. Jumlah sampel adalah tiga puluh lima perawat dan seratus empat puluh pasien. Teknik pengambilan sampel untuk perawat menggunakan total sampling, sementara untuk pasien dilakukan dengan consecutive sampling.

Perawat yang menjadi responden dalam penelitian ini ada dua, yaitu perawat dalam kelompok intervensi berasal dari $\mathrm{RS} \mathrm{X}$ dan perawat dalam kelompok kontrol berasal dari RS Y. Sementara pasien yang dirawat inap sebagai responden yang berasal dari RS X (kelompok intervensi) dan pasien yang dirawat inap sebagai responden berasal dari RS Y (kelompok kontrol).
Pada kelompok perlakuan diberi pelatihan tentang pelayanan prima, sedangkan kelompok kontrol tidak diberi pelatihan. Sebelum perlakuan terhadap kedua kelompok dilakukan melalui pengukuran awal (pretest) untuk tingkat kepuasan responden atau pasien. Setelah intervensi, dilakukan pengukuran akhir (post test) terhadap semua kelompok untuk menentukan efek perlakuan inap. pada responden yang dalam hal ini pasien rawat

Hasil analisis data univariat untuk data numerik disajikan dalam bentuk mean (rerata), median, standar deviasi, nilai maksimum-minimum, dan CI 95\%. Sementara data kategori disajikan dalam bentuk distribusi frekuensi dan proporsi. Selanjutnya dilakukan uji kesetaraan karakteristik pasien (umur, jenis kelamin, tingkat pendidikan, penghasilan, dan suku/budaya) dan karakteristik perawat (umur, status kepegawaian, dan tingkat pengetahuan) menggunakan uji Chi Square (CS). Hasil uji kesetaraan karakteristik pasien dan karakteristik perawat didapatkan data yang homogen. Kemudian dilanjutkan dengan analisis bivariat menggunakan uji Paired t-test. Penelitian ini sudah lulus uji etik di Fakultas Ilmu Keperawatan Universitas Indonesia (FIK UI).

\section{Hasil}

Intervensi yang dilakukan dengan memberikan pelatihan pelayanan prima berbasis budaya selama dua hari untuk dua gelombang. Pelatihan yang diberikan kepada perawat kelompok intervensi meliputi materi pelayanan prima, caring, komunikasi terapeutik, dan budaya. Setelah mendapatkan materi pelatihan dilakukan kegiatan role play, tentang cara komunikasi dengan pasien menggunakan dialek Papua, peserta disimulasikan sebagai pasien dan perawat. Kegiatan ini berlangsung selama dua jam, memang tidak semua peserta mendapat kesempatan untuk melakukan simulasi karena keterbatasan waktu pelatihan.

Kegiatan selanjutnya adalah pendampingan, pendampingan untuk perawat pelaksana dilakukan selama dua minggu, perawat diberikan pendampingan oleh peneliti dibantu oleh tiga kepala 
ruang. Kegiatan pendampingan meliputi kegiatan pelayanan prima berbasis budaya, seperti cara menyapa pasien dengan dialek Papua, cara menjelaskan informasi berkaitan dengan pelayanan keperawatan yang diberikan kepada pasien, cara memfasilitasi pasien jika ada kunjungan dari keluarga, tetangga, atau perkumpulan gereja. Kendala yang dihadapi pada saat pendampingan adalah kurangnya tenaga pendamping atau mentor sehingga hanya kepala ruang yang diharapkan bisa memberikan pendampingan. Jika kepala ruangan memiliki jadwal yang padat, seperti rapat, dan kegiatan sosialisasi, perawat pelaksana sedikit sekali mendapatkan bimbingan.

Kegiatan yang berkaitan dengan pelayanan prima berbasis budaya yang dilakukan di rumah sakit kelompok intervensi, yaitu dengan memfasilitasi pengunjung pasien yang membesuk untuk diberi waktu dalam memberikan doa kepada pasien. Pasien yang mendapat kunjungan dari kelompok gereja atau jemaatnya disiapkan ruangan khusus. Dalam kegiatan ini, sementara, ruangan yang dipakai adalah ruangan pertemuan perawat. Pasien yang mendapat kunjungan dari jemaat gereja di dorong ke ruangan tersebut, di sinilah para jemaat atau keluarga yang ingin mendoakan diberi waktu 15-20 menit untuk mendoakan agar pasien lekas sembuh. Ternyata kegiatan yang dilakukan seperti ini mendapatkan respons positif dari pasien dan keluarga serta pengunjung sehingga banyak keluarga dan pengunjung pasien yang menyatakan bahwa hal semacam ini baik dan tetap terus untuk ditingkatkan dan dipertahankan. Pelaksanaan kegiatan ini belum tersosialisasi dengan baik ke seluruh petugas sehingga ada yang melakukan dan ada yang tidak. Selain itu, belum adanya aturan yang tertulis berapa kali pasien diberi kesempatan, berapa lama waktu yang disediakan, dan perlu adanya pemberitahuan dari keluarga untuk bisa dijadwalkan dalam kegiatan harian perawat untuk memfasilitasi keluarga dalam memberikan doa kepada pasien sehingga tidak terjadi penumpukan atau jadwal yang sama dalam satu waktu.

Kegiatan pelayanan prima berbasis budaya yang lain adalah dengan menganalisis budaya masyarakat Papua yang biasa makan pinang, dan membuang ludah pinang di sembarang tempat. Berdasarkan hal tersebut, perawat berinisiatif untuk menyediakan suatu tempat yang sudah disiapkan, seperti bak pasir tempat membuang ludah pinang, para pasien atau pengunjung yang akan makan pinang diarahkan ketempat tersebut, secara fasilitas tempat tersebut masih perlu pembenahan agar representatif. Tanggapan dari keluarga pasien atau pengunjung juga baik, bahkan ada yang menyarankan agar ruangannya diperluas dan dibuat permanen sehingga para pengunjung dapat menikmatinya dengan nyaman.

Tabel 1 menunjukkan bahwa rerata skor kepuasan pasien sebelum intervensi adalah -8,81 dan rerata skor kepuasan pasien setelah intervensi menjadi 4,95. Hal ini menunjukkan adanya peningkatan rerata skor kepuasan pasien sebelum dan sesudah pelaksanaan intervensi pelatihan pelayanan prima berbasis budaya pada kelompok intervensi $(p=0,000)$. Artinya ada pengaruh pelatihan pelayanan prima berbasis budaya terhadap kepuasan pasien pada kelompok intervensi.

Tabel 1. Perbedaan Kepuasan Pasien Sebelum dan Sesudah Pelatihan terhadap Kelompok Intervensi dan Kontrol

\begin{tabular}{lcccc}
\hline & Mean & SD & CI 95\% & p \\
\hline Kelompok intervensi & & & & \\
a. Pretest & -8.81 & 14.226 & $-20,26-7,24$ & $\mathbf{0 , 0 0 1 *}$ \\
b. Postest & 4.95 & 14.795 & & \\
Kelompok kontrol & & & & \\
a. Pretest & 3,11 & 12,020 & $0,37-7,39$ & $\mathbf{0 , 0 7 5}$ \\
b. Postest & 0,41 & 8,930 & & \\
\hline
\end{tabular}

*bermakna pada $\alpha=0,05$ 
Hasil analisis pada Tabel 1 menunjukkan bahwa skor rerata kepuasan pasien sebelum intervensi di kelompok kontrol terjadi penurunan tingkat kepuasan pasien sebelum dan sesudah pelatihan pelayanan prima berbasis budaya kontrol.

\section{Pembahasan}

Hasil penelitian menunjukkan bahwa rerata skor kepuasan pasien sebelum intervensi dan setelah intervensi mengalami peningkatan satu setengah kali lipat lebih puas dari kondisi awal. Artinya ada pengaruh pelatihan pelayanan prima berbasis budaya terhadap kepuasan pasien pada kelompok intervensi. Komunikasi perawat terhadap pasien menjadi faktor yang penting dalam pemberian pelayanan prima berbasis budaya.

Pelayanan prima menurut Budiono (2012) adalah pelayanan jasa yang dapat membuat pelanggan merasa mendapatkan pelayanan sesuai harapan, sesuai dengan indikator yang ditentukan serta dapat dipertanggungjawabkan, sehingga merasa puas. Pelayanan prima harus memberikan yang terbaik bagi pelanggan, melakukan apapun yang mungkin untuk memuaskan pelanggan, serta membuat keputusan yang dapat memberikan keuntungan pada pelanggan tapi tidak merugikan perusahaan (Gerson, 2011). Pelayanan prima dilaksanakan dalam rangkaian kegiatan secara utuh yang bersifat wajar, lancar, terbuka, sederhana, tepat sasaran, terjangkau, lengkap, dan tidak rumit.

Menurut Narayanasamy (2002), “Caring” yang berdasarkan kebudayaan adalah aspek asensial untuk mengobati dan menyembuhkan dimana pengobatan tidak akan mungkin dilakukan tanpa perawatan, sebaliknya perawatan dapat tetap eksis tanpa pengobatan. Konsep keperawatan kultural, arti, ekspresi, pola-pola, proses, dan struktur dari bentuk perawatan transkultural yang beragam dengan perbedaan dan persamaan yang ada. Setiap kebudayaan manusia memiliki pengetahuan dan praktik keperawatan tradisional serta praktik profesional yang bersifat budaya dan individual.

Pelayanan prima dalam keperawatan adalah pelayanan yang didasari oleh tindakan caring terhadap pasien dan keluarga. Akhtari-Zavare, Abdullah, Hassan, Said, dan Kamali (2010) menjelaskan caring adalah esensi dari keperawatan yang berarti juga pertanggung jawaban hubungan antara perawat dengan klien, dimana perawat melibatkan klien untuk berpartisipasi dalam memperoleh pengetahuan, dan meningkatkan derajat kesehatan. Caring adalah kegiatan langsung untuk memberikan bantuan, dukungan perilaku kepada individu atau kelompok melalui antisipasi kebutuhan untuk meningkatkan kondisi manusia atau kehidupan (Leininger \& McFarland, 2002).

Praktik perawatan yang berbasis nilai budaya dipengaruhi oleh bahasa, filosofi, agama, kekeluargaan, sosial, politik, pendidikan, ekonomi, teknologi, etnohistory, dan lingkungan. Keuntungan dari keperawatan yang berbasis budaya dapat memberikan kepuasan kepada pasien sehingga mempengaruhi derajat kesehatan dan kesejahteraan individu, keluarga, kelompok, dan komunitas di dalam lingkungannya. Kebudayaan dan keperawatan yang seimbang dapat terwujud apabila pola dan nilai-nilai perawatan digunakan secara tepat, aman dan bermakna (Beach, et al., 2006).

Faktor komunikasi. Komunikasi adalah sesuatu untuk dapat menyusun dan menghantarkan suatu pesan dengan cara yang gampang sehingga orang lain dapat mengerti dan menerima (Nursalam, 2002). Komunikasi dalam praktik keperawatan profesional merupakan unsur utama bagi perawat dalam melaksanakan pelayanan keperawatan untuk mencapai hasil yang optimal. Adapun faktor-faktor yang mempengaruhi penerapan komunikasi terapeutik antara lain: pendidikan, lama bekerja, dan pengetahuan, sikap dan kondisi psikologi (Sumijatun, 2011).

Komunikasi yang baik dalam pelayanan prima yang berkualitas akan membuat pasien menjadi puas. Suatu pelayanan dinilai memuaskan apabila pelayanan tersebut dapat memenuhi kebutuhan dan harapan pelanggan. Jika pelanggan merasa tidak puas terhadap suatu pelayanan yang disediakan, maka pelayanan tersebut dapat dipastikan tidak efektif dan tidak efisien 
(Suryawati, 2006). Supranto (2006) mengemukakan bahwa jika pelayanan keperawatan yang dirasakan tidak sesuai dengan harapan maka pasien akan merasakan ketidakpuasan terhadap layanan tersebut dan akan menimbulkan keluhan atau klaim dari pasien.

Menurut Bail (2008) mengemukakan bahwa ketidakpuasan pasien dalam menerima pelayanan keperawatan berhubungan dengan ketidakjelasan prognosis, ketidakjelasan penyampaian informasi, dan pembuatan keputusan. Tingkat kepuasan pasien mengalami peningkatan setelah perawat mendapatkan pelatihan tentang pelayanan prima berbasis budaya, artinya bahwa ada pengaruh intervensi tentang pelayanan prima berbasis budaya terhadap tingkat kepuasan pasien.

Rumah sakit mempunyai tanggung jawab untuk selalu meningkatkan kepuasan pasien sehingga rumah sakit juga mempunyai tanggung jawab untuk meningkatkan pengetahuan, sikap, dan tindakan perawatnya agar dapat memberikan pelayanan prima kepada pasien maupun keluarga.

\section{Kesimpulan}

Intervensi yang diberikan tentang pelayanan prima berbasis budaya local, khususnya budaya Papua seperti menyediakan tempat khusus bagi keluarga dan para pengunjung untuk memberikan doa bagi pasien yang sakit, menyediakan bak pasir tempat membuang ludah pinang, dan membudayakan perawat agar dalam berkomunikasi dengan pasien memakai dialek Papua mendapat respons yang baik oleh pasien, keluarga maupun pengunjung yang datang.

Tingkat pengetahuan perawat terkait pelayanan prima terhadap kelompok intervensi sebelum dan sesudah pelatihan pelayanan prima ada peningkatan sebesar dua kali lipat, demikian juga hasil observasi yang dilakukan terhadap perawat yang melakukan pelayanan prima berbasis budaya terdapat peningkatan sebesar tiga kali lipat jika dibandingkan dengan sebelumnya. Peningkatan tersebut terjadi karena perawat telah mendapatkan pelatihan berupa teori, juga mendapatkan bimbingan selama dua minggu sehingga ilmu yang didapat setelah pelatihan dapat diaplikasikan kepada pasien sehingga meningkatkan kepuasan pasien yang dirawat. Sikap dan perilaku perawat juga mengalami perubahan dari yang kurang care menjadi lebih care terhadap pasien, lebih ramah dengan pasien, penampilan perawat juga menjadi lebih baik, cara komunikasi lebih efektif dengan pasien dan sebagian perawat sudah mulai menggunakan dialek Papua ketika berinteraksi dengan pasien, khususnya pasien yang berasal dari suku Papua.

Hasil penelitian menunjukkan bahwa tingkat kepuasan pasien terhadap kelompok intervensi terjadi peningkatan jika dibandingkan antara sebelum pelatihan dan setelah pelatihan. Hal ini terjadi karena pemberian pelayanan prima berbasis budaya yang dilakukan oleh perawat dapat diterima dan sesuai dengan budaya lokal di Papua, artinya dalam pemberian pelayanan prima, kita perlu mempertimbangkan budaya lokal yang tidak dapat kita hilangkan, tetapi dapat kita modifikasi sehingga antara budaya dan pelayanan dapat berjalan seiring, tujuan akhirnya adalah kepuasan bagi pasien, keluarga maupun pengunjung $(\mathrm{HH}, \mathrm{TN})$.

\section{Referensi}

Bail, K. (2008). Patient and professional dissatisfaction: A literature review of prognosis communication related to hospital settings. Contemporary Nurse, 29 (2), 135-146.

Budiono. (2012). Pelayanan Prima dalam memuaskan konsumen. Yogyakarta: Penerbit Buku Kedokteran EGC.

DeRosa, N., \& Kochurka, K. (2006). Implement culturally competent healthcare in your workplace. Nursing Management, 37(10), $18-26$

Douglas, M.K., Pierce, J.U., Rosenkoetter, M., Callister, L.C., Hattar-Pollara, M., Lauderdale, J. \& Pacquiao, D. (2009). Standards of practice for culturally competent nursing care: A request for comments. Journal of Transcultural Nursing, 20, 257-269. doi: 10.1177/1043659609334678 
Foster, G., \& Anderson, B. (2009). Antropologi kesehatan. (Priyanti Suryadarma dan Meutia F Hatta, Penerjemah). Jakarta: Universitas Indonesia.

Gerson, F.R. (2011). Beyound customer service, program-program untuk mempertahankan pelanggan. Jakarta: Lutan Edukasi.

Gulbu, T. (2006). The implications of transcultural nursing models in the provision of culturally competent care. Icus Nurs Web J, 25, 1-11.

Bhui, K., Warfa, N., Edonya, P., McKenzie, K., \& Bhugra, D. (2007). Cultural competence in mental healthcare: A review of model evaluations. BMC Health Serv Res., 7 (15), 1-10. doi: 10.1186/1472-6963-7-15.

Leininger, M., \& McFarland, M.R. (2002). Transcultural nursing: Concepts, theories, research, and practice. United States: The McGraw-Hill Companies.

Maier-Lorentz, MM. (2008). Transcultural nursing is importance in nursing practice. Journal of Cultural Diversity, 15 (1), 37-43.

Beach, M.C., Gary, T.L., Price, E.G., Robinson, K., Gozu, A., Palacio, A., Smarth, C., Jenckes, M., Feuerstein, C., Bass, E.B., Powe, N.R., \& Cooper, L.A. (2006). Improving health care quality for racial/ethnic minorities: A systematic review of the best evidence regarding provider and organization interventions. BMC Public Health, 24 (6) 104.

Akhtari-Zavare, M., Abdullah, M.Y., Hassan, T.S., Said, S.B., \& Kamali, M. (2010). Patient satisfaction: Evaluating nursing care for patients hospitalized with cancer in Tehran Teaching Hospitals, Iran. Global Journal of Health Science, 2 (1), 117-126.

Narayanasamy, A. (2002). The ACCESS model: A transcultural nursing practice framework. $\mathrm{Br}$ J Nurs, 11 (9), 643-650.

Raso, R. (2006). Cultural competence: Integral in diverse populations. Journal of Nursing Management, 37 (7), 56.

Sumijatun. (2011). Membudayakan etika dalam praktek keperawatan. Jakarta: Medika Salemba.

Supranto, J. (2006). Pengukuran tingkat kepuasan pelanggan untuk menaikkan pangsa pasar. Jakarta: Rineka Cipta.

Suryawati, C., Dharminto., \& Zahroh, S (2006). Penyusunan indikator kepuasanpasien rawat inap rumah sakit di propinsi Jawa Tengah. Jurnal Manajemen Pelayanan Kesehatan, 9 (4), 177-184.

Watson, J. (2002). Caring science as sacred science. Philadelphia: Davis Company. 